\title{
A NOTE ON A CERTAIN BIVARIATE MEAN
}

\section{EDWARD NEUMAN}

Abstract. Weighted arithmetic or geometric means of two bivariate means are used to obtain lower and upper bounds for a bivariate mean introduced by Neuman and Sándor. Bounds involving weighted arithmetic means are sharp.

Mathematics subject classification (2010): 26 D07.

Keywords and phrases: Bivariate means, inequalities, hyperbolic functions.

\section{REFERENCES}

[1] H. AlzER, S.-L. QIU, Monotonicity theorems and inequalities for complete elliptic integrals, J. Comput. Appl. Math. 172 (2004), 289-312.

[2] B. C. CARLson, Algorithms involving arithmetic and geometric means, Amer. Math. Monthly 78 (1971), 496-505.

[3] Y.-M. CHU, Y.-F. QIU, M.-K. WANG, Sharp power mean bounds for the combination of Seiffert and geometric means, Abstract Appl. Anal. 2010, Article ID 108920, 12 pages.

[4] Y.-M. CHU, Y.-F. QIU, M.-K. WANG, G.-D. WANG, The optimal convex combination of arithmetic and harmonic means for the Seiffert's mean, J. Inequal. Appl. 2010, Article ID 436457, 7 pages.

[5] Y.-M. CHu, C. Zong, G.-D. WANG, Optimal convex combination bounds of Seiffert and geometric means for the arithmetic mean, J. Math. Inequal. 5 (2011), 429-434.

[6] S.-Q. GAO, H.-Y. GAO, W.-Y. SHI, Optimal convex combination bounds of the centroidal and harmonic means for the Seiffert mean, Int. J. Pure Appl. Math. 70 (2011), 701-709.

[7] W.-D. JIANG, Some sharp inequalities involving reciprocals of the Seiffert and other means, J. Math. Inequal., to appear.

[8] B.-Y. Long, Y.-M. CHU, Sharp bounds for the Neuman-Sándor mean in terms of generalized logarithmic mean, submitted.

[9] D.S. Mitrinović, Analytic Inequalities, Springer-Verlag, Berlin, 1970.

[10] E. Neuman, Inequalities for the Schwab-Borchardt mean and their applications, J. Math. Inequal. 5, 4 (2011), 601-609.

[11] E. Neuman, On one-parameter family of bivariate means, Aequat. Math. 83, 1-2 (2012), $191-197$.

[12] E. Neuman, J. SÁndor, On the Schwab-Borchardt mean, Math. Pannon. 14, 2 (2003), $253-266$.

[13] E. Neuman, J. SÁndor, On the Schwab - Borchardt mean II, Math. Pannon. 17, 1 (2006), 49-59.

[14] E. NEUMAN, J. SÁNDOR, On some inequalities involving trigonometric and hyperbolic functions with emphasis on the Cusa-Huygens, Wilker, and Huygens inequalities, Math. Inequal. Appl. 13 (2010), $715-723$.

[15] E. Neuman, J. SÁndor, Bounds for the quotients of differences of certain bivariate means, Adv. Studies Contemp. Math., to appear.

[16] Zs. PÁles, Inequalities for sums of powers, J. Math. Anal. Appl. 131 (1988), 265-270.

[17] S. Ponnus amy, M. Vuorinen, Asymptotic expansions and inequalities for hypergeometric functions, Mathematika 44 (1997), 43-64.

[18] H.-J. SeIfFERT, Problem 887, Nieuw. Arch. Wisk. 11 (1993), 176.

[19] H.-J. SEIFFERT, Aufgabe 16, Würzel 29 (1995), 87. 